NBER WORKING PAPER SERIES

EQUILIBRIUM FICTIONS:

A COGNITIVE APPROACH TO SOCIETAL RIGIDITY

\author{
Karla Hoff \\ Joseph E. Stiglitz \\ Working Paper 15776 \\ http://www.nber.org/papers/w15776
NATIONAL BUREAU OF ECONOMIC RESEARCH
1050 Massachusetts Avenue
Cambridge, MA 02138 \\ March 2010
}

We thank Roland Bénabou and Varun Gauri for valuable comments, and Alana Bevan and Rebecca Wieters for excellent research assistance. Financial support from the World Bank is gratefully acknowledged. This paper is a much shortened version of an earlier paper. The views expressed here are those of the authors and not necessarily those of the World Bank or the National Bureau of Economic Research.

NBER working papers are circulated for discussion and comment purposes. They have not been peerreviewed or been subject to the review by the NBER Board of Directors that accompanies official NBER publications.

(C) 2010 by Karla Hoff and Joseph E. Stiglitz. All rights reserved. Short sections of text, not to exceed two paragraphs, may be quoted without explicit permission provided that full credit, including $\odot$ notice, is given to the source. 
Equilibrium Fictions: A Cognitive Approach to Societal Rigidity

Karla Hoff and Joseph E. Stiglitz

NBER Working Paper No. 15776

February 2010

JEL No. N10,O43,Z13

\begin{abstract}
This paper assesses the role of ideas in economic change, combining economic and historical analysis with insights from psychology, sociology and anthropology. Belief systems shape the system of categories ("pre-confirmatory bias") and perceptions (confirmatory bias), and are themselves constrained by fundamental values. We illustrate the model using the historical construction of racial categories. Given the post-Reformation fundamental belief that all men had rights, colonial powers after the 15th century constructed ideologies that the colonized groups they exploited were naturally inferior, and gave these beliefs precedence over other aspects of belief systems. Historical work finds that doctrines of race came into their own in the colonies that became the US after, not before, slavery; that out of the "scandal of empire" in India emerged a "race theory that cast Britons and Indians in a relationship of absolute difference"; and that arguments used by the settlers in Australia to justify their policies towards the Aborigines entailed in effect the expulsion of the Aborigines from the human race. Racial ideology shaped categories and perceptions in ways that we show can give rise to equilibrium fictions. In our framework, technology, contacts with the outside world, and changes in power and wealth matter not just directly but because they can lead to changes in ideology.
\end{abstract}

\author{
Karla Hoff \\ World Bank \\ MC 3-301 \\ 1818 H St NW \\ Washington DC 20433 \\ khoff@worldbank.org \\ Joseph E. Stiglitz \\ Uris Hall, Columbia University \\ 3022 Broadway, Room 814 \\ New York, NY 10027 \\ and NBER \\ jes322@columbia.edu
}




\section{Equilibrium Fictions: A Cognitive Approach to Societal Rigidity}

Karla Hoff and Joseph E. Stiglitz

Psychologists, sociologists, and anthropologists have emphasized that the cognitive frames within which people view the world are both collectively held and malleable over time. Category systems have cultural roots and influence what attributes people perceive (surveys are Eric Margolis and Stephen Laurence 1999 and Bertrand, Chugh, and Mullainathan 2005). The cognitive frames operative in a culture unconsciously influence, as well, how people interpret whatever information they register (see, e.g., Mary Douglas 1987). Yet economists have generally neglected the role played by socially constructed cognitive frames. For instance, in rational expectations (hereafter, RE), each individual is assumed to use all relevant information in an unbiased way.

However, two economists have called attention to social constructs in accounting for development. Gunnar Myrdal (1968) argued that "irrational beliefs" in South Asia bred social inertia. Douglass North (2005), drawing on cognitive science, argued that perception is always an interpretation that is shaped by the belief systems of the society. Drawing on economic history, he argued that those belief systems are a key determinant of economic development. 
Recently, economic theorists have investigated the consequences of the endogeneity of cognitive frames (see, e.g.,Roland Bénabou and JeanTirole 2006 and Bénabou 2008). They have modeled individuals as trading off the motivational or hedonic benefits of suppressing certain kinds of information, against the possible biases in action that that may cause. Recent discussions of macro-economics have assigned a role to Keynesian "animal spirits"-emotions that influence confidence_-giving almost unfettered scope to changes in beliefs.

In our approach, the infinite set of potentially observable data and the infinite ways in which that data could be processed are limited by the finite set of socially constructed categories that make up a part of what are called ideologies. These categories are a state variable, which cannot be changed in the short run. These "lenses" even affect views about whether there is a need for change. Incorporating this perspective helps explain why institutional change can be so difficult and societies so rigid. A set of beliefs that may have been functional at one time, but is no longer so, can persist after the economics/technology that had led to the adoption of the beliefs has changed. We explain how even a fiction can be supported as an equilibrium. In the equilibrium, individuals' beliefs affect their behavior and perceptions. We show that allowing for "equilibrium bias" in perceptions increases the range of beliefs that can be sustained in equilibrium and may explain the existence across time periods and across societies of very different 
ideologies. This approach allows for a larger and more robust set of equilibria than can be supported by a RE model. On the other hand, the set of equilibria in our approach is much more constrained than the "animal spirits" equilibrium, which presumes that virtually any set of beliefs could be sustained.

While this paper does not provide a fully articulated model of the evolution of ideologies, it does present a framework that suggests some key determinants. Because belief systems affect the equilibrium, e.g., by shaping perceptions, elites have a strong incentive to influence people's beliefs. In contrast, in a RE equilibrium, this is not relevant-cognitive frames play no role. But beliefs may also constrain the set of equilibria relative to what might emerge if elites could determine the rules in their own self-interest. The elites cannot simply "choose" the cognitive frames that work best for themselves (nor can non-elites simply choose the beliefs that might work best for themselves). The task of "choosing" for themselves and imposing on others cognitive frames is more complicated and is itself constrained by higher-order beliefs. Those in "power" control some beliefs, and while they may attempt to do so they typically do not control all the determinants of the evolution of beliefs. Cultures are always contested.

Incorporating beliefs as state variables provides part of a general theory of social change that is markedly different from traditional theories, in which only capital and the distribution of power and wealth are state variables. If beliefs 
change, the equilibrium can change, with no change in the "fundamentals."

We use the example of the construction of racial categories to illustrate the idea of an equilibrium social construct (ideology). Section I discusses historical instances. Section II presents a model in which differentially biased cognition helps sustain the idea of race. Section III formalizes the notion of an equilibrium social construct.

\section{Historical examples of the collective determination of racial categories}

The construction of race to justify slavery. Skin color was not initially an organizing principle in the colonies that became the US. There were multiple categories of coerced labor, and freedom and slavery were not yet associated with persons of white and black skin. In the $17^{\text {th }}$ century,

“a substantial number of Virginia's Negroes were free or became free. And all of them, whether servant, slave, or free, enjoyed most of the same rights and duties as other Virginians. ... They could sue and be sued in court. They did penance in the parish church for having illegitimate children.” (Morgan,1972, p. 18)

Racist codes and beliefs emerged in the late seventeenth century, as the economics of slavery changed. After 1660, Virginia's death rate, which had been "comparable only to that found in Europe during the peak years of a plague," fell sharply. Two consequences were that "an investment in slave labor was much more profitable than an investment in free labor," and the engrossment of 
Virginia’s lands kept many former servants landless and impoverished (Morgan pp. 19, 25). In Bacon's Rebellion of 1676, Virginia's “Poore Endebted Discontented and Armed" turned against the elite in a plundering expedition that spread across the entire state (p. 22). The fear of unrest contributed to the decline in the reliance on indentured servants and to the abridgement of the liberties of Africans. "To keep as slaves black men who arrived in that condition was possible and apparently regarded as plain common sense” (p. 25). Some states forbade anyone to teach even a free black to read and write. In 1712, South Carolina passed laws that became the model for slave codes in the South. They forbade schooling, travelling, church attendance, land ownership, and inter-marriage. Yet given emerging Enlightenment ideologies, oppression came to need justification. David Brion Davis (1975) argues that at the very point in time when large numbers of men and women were beginning to question the moral legitimacy of slavery, the idea of race came into its own. Out of this process, the project of creating two fictions emerged. The first fiction was the biological inequality of human beings. The second was the natural discontinuity between the categories, "white" and "black." Many states went the way of the Virginia statute which, as revised in 1924, "classified as white only a person 'who has no trace whatsoever of blood other than Caucasian'” (Hollinger 2003, p, 1369). In these ways, race emerged as a social construct. 
The British imperial narrative in India. The East India Company in the $18^{\text {th }}$ century "had become a rogue state: waging war ... and collecting revenue over Indian territory" that produced massive private fortunes and contributed to famine in Bengal in 1770 (Nicholas B. Dirks, 2006, p. 13, 252). Parliamentary inquiries brought the scandal to national attention. They culminated in the trial of the governor of India, Warren Hastings. In his opening speech, Edmund Burke declared, “'I impeach him in the name of the English Constitution, which he has violated and broken,--I impeach him in the name of Indian Millions, whom he has sacrificed to injustice.” Burke protested against Hastings’ “'Geographical morality”: “'We think it necessary in justification of ourselves to declare that the laws of morality are the same everywhere’” (Dirks, pp. 105, 196,107). But over the nine years of the trial, the idea that British law applied to agents of Britain in India was salvaged not by finding Hastings guilty (he was acquitted) but instead by inventing a new interpretation of India: "the social, political, cultural, and economic buoyancy of India in the $18^{\text {th }}$ century was not just forgotten but suppressed." "Built on fabrication, colonial history imputed barbarism to justify, and even ennoble, imperial ambition.” "Scandal became normalized in the assumptions and categories of modernity itself" (Dirks, pp. xii,.5, 29). What emerged was a "race theory that cast Britons and Indians in a relationship of absolute difference” (Dirks, 2001, p. 133). 
The emergence of a racial idiom for Native Americans. In the mid-17th century, it was still common to argue that "NNature knowes no difference between Europe and Americans in blood, birth, bodies, \&c'” (Chaplin 1997, p. 245 citing a 1656 source). But by the 18th century,

"[t]he English contended that the Indians were ill-adapted to any region" [and] "used that explanation to usurp the very habitat of Americas" preColumbian natives.... English discourses of nature and the human body were fundamental to their imperial project. The proof was in the body." "These beliefs [of Indians' physical inferiority] were not universal, nor did they fail to elicit disagreement...But a good measure of the persuasiveness of the argument for English physical superiority was the fact that it appeared even in the writings of colonists who were sympathetic to Indians and who otherwise argued for native hardiness” (Chaplin, pp. 248, 232-233, 250).

The "expulsion" of Australian Aborigines from the human race. Aborigines were classified as British subjects. "The early governors [in the 17th century] wanted to see them converted to Christianity and farming ...- -an idea loathed and resisted by every white [settler], no matter what his class” (Robert Hughes, 1987, p. 275). One historian characterizes the arguments used by the settlers to justify their policies towards the Aborigines as entailing the expulsion of the Aborigines from the human race (Humphrey McQueen, 1971, p. 115). Colin M. Tatz (1972, p. 99) describes over 30 statutes in Australia that ascribe certain characteristics, usually negative, to Aborigines, including the inability to manage their own affairs and property and to govern their communities. 
By the Age of Revolution, oppression both called for a justification and narrowed the basis on which such a justification might rest to one based on the slaves' or the natives' innate inferiority, ${ }^{1}$ a " "presumed incapacity for freedom... that crystallized into a racial one with all its subsequent pseudobiological trappings” (Barbara Fields, 1982, p. 162). As Montesquieu quipped, “'It is impossible for us to suppose that these beings should be men; because if we suppose them to be men, one would begin to believe that we ourselves were not Christians"” (Davis, p 302). This dilemma did not occur, or at least not to the same extent, in earlier periods and in other regions. In antiquity, natural philosophy in general stressed "an underlying, universal human similarity” (Chaplin, p. 230) and yet saw no wrong in enslaving prisoners of war and colonized peoples. When the Athenians landed on the island of Melos, the Melians asked for mercy, invoking their goodness in the eyes of the gods. But the Athenians killed all the men, sold the women and children as slaves, and colonized the island, justifying their action this way: "right, as the world goes, is only in question between equals in power, while the strong do what they can and the weak suffer what they must” (Thucydides c. 431 BC, Book 5.89).

After the $15^{\text {th }}$ century, racial categories were constructed and given precedence over other aspects of belief systems in which slavery might be viewed as

\footnotetext{
${ }^{1}$ As noted by David Hume (1751, p. 45).
} 
unacceptable. The categories came to be represented as "God-given." They were entrenched and embedded in individuals' minds through symbolism and protocol. Strictly enforced codes of interracial etiquette reminded the subordinate group of its place. For example, in Australia, "the racialized designation of space expressed and reproduced social and ontological categories on which colonial society was founded” (Gillian Cowlishaw 1999, p. 63, emphasis added). In the Jim Crow South, the unwritten rules that governed day-to-day interactions across race lines have been seen "not only as a form of social control but also as a script for the performative creation of culture and of 'race' itself”(Jennifer Ritterhouse, 2006, p. 4). As Charles Evers, brother of the murdered civil rights activist Medgar Evers, explained in his autobiography, “'Our mothers began telling us about being black from the day we were born'” (cited in Ritterhouse, p.5). Histories in which the subordinate group had played a different role, were suppressed (e.g., the Indians in pre-colonial Bengal or the history of biracial political parties in the US in the 1880s).

\section{A Model of Inequality Based on Fictions}

This section expands on Olivier Compte and Andrew Postlewaite (2004)'s model of confidence-enhanced performance and biased perception to show how a fiction can be maintained in equilibrium. The model rests on three hypotheses, 
each supported by empirical evidence. The first is called confirmatory bias: People tend to misread evidence as additional support for initial hypo-theses. Experiments demonstrate "how providing the same ambiguous information to people who differ in their initial beliefs on some topic can move their beliefs farther apart" (see Matthew Rabin and Joel L. Shrag 1999 for a review and model). This bias can also explain how individuals, with favorable prior beliefs about themselves, can maintain an inflated view of themselves.

We call the second hypothesis pre-confirmatory bias: When people draw inferences, they begin with a specification that posits certain categories, e.g., racial categories, that they do not individually choose (Glenn Loury 2002, ch. 2). The third hypothesis is that self-confidence boosts performance. For example, in three separate experiments, Pamela K. Smith et al. (2008) find that the perception that one is low in the social hierarchy lowers performance in complex tasks.

A recent set of experiments with junior high school boys in India illustrates the interaction among these hypotheses. Children in castes that were traditionally Untouchable can solve mazes as well as high-caste children (Hoff and Pandey 2006). Yet when students' caste identities are publicly revealed, the performance of the low caste falls both absolutely and relative to the performance of the high caste. We infer that in other possible worlds, the Untouchables could have been an equal or dominant group. There are no intrinsic ability differences by caste. It is 
clear that a social construct has affected behavior.

In our model, individuals undertake a series of projects, at each of which they can fail or succeed. Confidence, based on a person's perception $\varphi$ of his empirical frequency of past success, affects the probability of success $\rho$ in future attempts, in ways that may be beyond his conscious control. Figure 1 shows the relationship $\rho=$ $\rho(\varphi)$. Under the assumptions of RE, there would be a unique equilibrium at the point marked RE, where the 45 degree line intersects the curve $\rho(\varphi)$.

\section{Figure 1. Equilibrium with rational expectations (at RE) and with biased perceptions (at points $r$ and $g$ )}

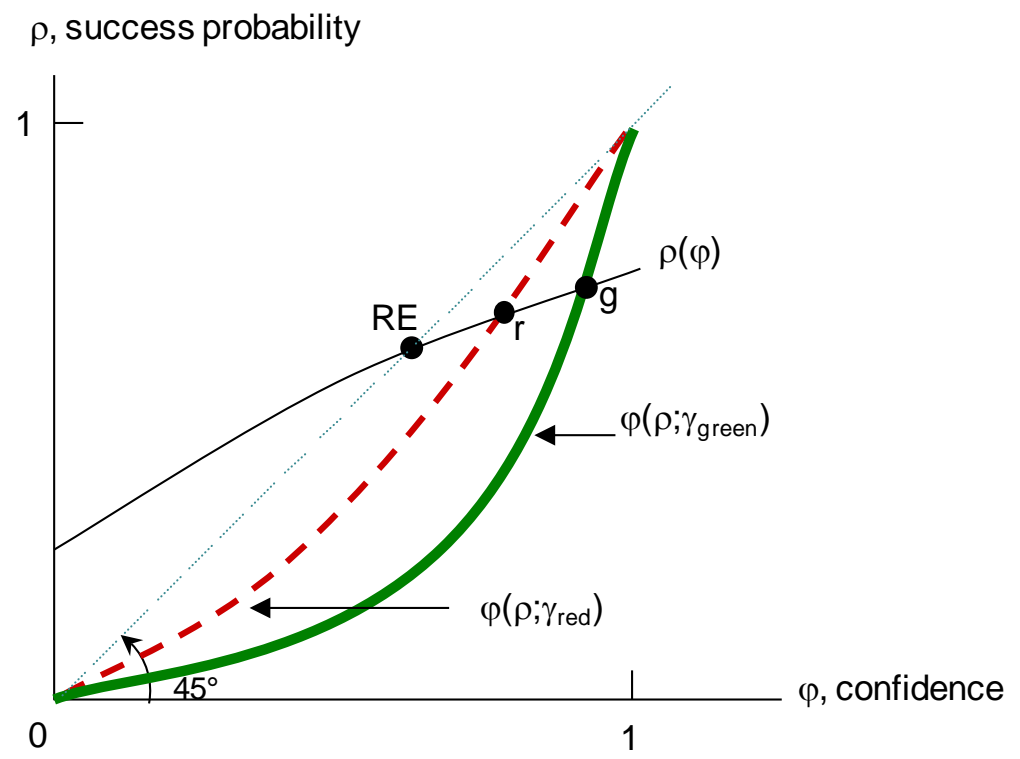

However, this will not be an equilibrium if an individual "forgets," or rationalizes as uninformative of future success, his failures with probability $\gamma>0$. 
Frequencies of success are random variables. But in the long run, a true frequency of success $\rho$ will translate into a perceived frequency of success whose distribution is concentrated around a single value, which we denote by $\varphi(\rho ; \gamma)$.

There are two races, red and green. The critical hypothesis is that reds are less able to "forget" experiences of failure: $\gamma_{\text {red }}<\gamma_{\text {green }}$. The interpretation of this hypothesis is as follows. Pre-confirmatory bias means that racial categories are salientthe reds see themselves as red, the greens as green. The reds have historically been treated as inferior, and this affects their perception of themselves-how they interpret experiences of failure (confirmatory bias). The reds see failures as confirming their (socially constructed) perceptions of inferiority, while the greens dismiss a large fraction of their failures because such failures are not consistent with their prior beliefs.

Equilibrium is the intersection of the production function, $\rho(\varphi)$, and a perception function, $\varphi(\rho ; \gamma)$. In the equilibrium, beliefs generate a level of performance that is consistent with those beliefs, given the bias in perceptions. The result is that a social construct will be self-fulfilling. The equilibrium at point $g$ in the figure corresponds to better performance than that at $\mathrm{r}$. 


\section{A Model of an Equilibrium Fiction and the Dynamics of Changes in}

\section{Beliefs}

The preceding section modeled a short-run equilibrium, given a social construct, namely, a racial ideology. Here we present a simple model in which beliefs, however they originate, affect behavior, and we formalize the idea of an equilibrium social construct. There are three levels of "cognition" or belief systems in the model: first, a "lens" through which individuals process data (called ideology), which we denote by $S$; using that lens, a set of beliefs about particulars, e.g. I am competent, which we denote by $A_{i}$ for agent $i$; and third, an überideology that affects individuals' judgments about the adequacy of their ideology $(U)$. Letting boldface letters denote vectors (so e.g., $A$ corresponds to the vector $\left(A_{1}, A_{2}, A_{3}, \ldots\right)$ ), the structure at time $t$ is

$$
\boldsymbol{A}_{t}=\mathrm{F}\left(\boldsymbol{Q}_{t}, S_{t}\right), \quad \boldsymbol{Q}_{t}=\mathrm{G}\left(\boldsymbol{X}_{t}, \boldsymbol{A}_{t}\right), \quad \text { and } \quad \boldsymbol{X}_{t}=\mathrm{H}\left(\boldsymbol{A}_{t}, S_{t}\right)
$$

The short-run equilibrium modeled in the previous section takes the state variable $S_{t}$ as fixed. Dropping the subscript $t$ on $S$, an individual's particular beliefs at time $t\left(A_{i, t}\right)$ are a function of outcomes $\boldsymbol{Q}_{\boldsymbol{t}}$ and the "lens" $S$. Outcomes are a function of behaviors by each agent (denoted $X_{i, t}$ ) and particular beliefs. And individual behaviors are a function of the particular beliefs as mediated through the lens. For example, in the Indian experiments in puzzle-solving, the "behavior" may have been effort. Particular beliefs $A_{i, t}$ may affect outcomes in other ways, too: Low-caste individuals may 
generate worse outcomes, e.g., number of puzzles solved, when their caste identities are publicly revealed, because of anxiety or other psychological factors.

The second and third equations can be combined to give

$$
\boldsymbol{Q}_{t}=\mathrm{G}\left[\mathrm{H}\left(\boldsymbol{A}_{t}, S\right), \boldsymbol{A}_{t}\right]=\mathrm{Z}\left(\boldsymbol{A}_{t}, S\right)
$$

A short-run equilibrium, e.g., an equilibrium fiction, is defined by a value of A that satisfies, for a particular S:

$$
\boldsymbol{Q}^{*}=\mathrm{Z}\left(\boldsymbol{A}^{*}, S\right) \quad \text { and } \quad \boldsymbol{A}^{*}=\mathrm{F}\left(\boldsymbol{Q}^{*}, S\right) \text {. }
$$

This equilibrium departs from rational expectations in just one respect: It posits biased perceptions of which an individual is not aware. The bias arises because of the ideology. This pair of equations states that, given an S (ideology), people will generate outcomes that are consistent with their beliefs.

There is a dynamic process, which generally occurs at a slow speed:

$$
S_{t+1}=\chi\left(S_{t}, U_{t}, T_{t}, V_{t}\right) \text {, }
$$

where $U_{t}$ is the überideology, $T_{t}$ is the "economic regime” (technology and wealth distribution), and $\boldsymbol{V}_{t}$ is a vector of other variables, e.g., encounters with other civilizations and their belief systems. We will not model in detail the evolution of ideologies $\left(S_{t}\right)$. That process, and even more so the evolution of the überideology, 
are idiosyncratic. ${ }^{2}$ Losing a war might lead to a change in views about racial superiority. An encounter with a different civilization-people who see the world through a different lens_-might make individuals aware of the possibility that their own lens is distorted. As we noted earlier, there may be pressures for ideologies to change when the elites discover that there is another belief system that does a better job in maximizing their well-being. The elites may not have sufficient control over the processes by which ideologies get formed to do so, though of course, they can use rituals and censorship to exert some influence on the ideology operative in society. In a democratic society, how that is done may be affected by the "median voter" as much as by elites. But there is no reason to believe that belief systems evolve as if they were chosen by a critical decision maker. They may be part of an (inefficient) Nash equilibrium, one that does not serve well the interests of any group.

Ideologies and individual observations of outcomes, themselves mediated through ideology, can provide a set of "conceivable” belief systems, among which individuals choose: $S_{i, t+1}$ is chosen by individual $i$ at time $t+1$ from a set $\Omega\left(S_{t}, A_{t}\right.$, $U_{t,} \Lambda(Q, A, S)$ ), where the set is defined (constrained) by the previous ideology and beliefs, the überideology, and the perception of outcomes $\Lambda$ as mediated through ideology and beliefs. This is methodological individualism. These “choices,” like

\footnotetext{
${ }^{2}$ For instance, notions of equality may have been championed by new economic interests to promote free markets, but the evolution of these ideas may also have been affected by the evolution of deeper, philosophical or religious ideas. The framework we set forth is consistent with these alternative interpretations.
} 
other individual decisions, are affected by the social construct. But these individual “choices” get aggregated into a new social construct:

$$
S_{t+1}=\widehat{\Phi}\left(S_{1, t}, S_{2, t}, S_{3, t}, \ldots S_{i, t}, \ldots, U_{t}, T_{t}, V_{t}\right)
$$

There is a medium-term equilibrium in which there is no tendency for society's belief system to change. The beliefs that we model here occur at two levels: individuals have beliefs about the nature of society, racial differences, etc., but those beliefs are turned into social constructs ("belief systems") through the kinds of mechanisms illustrated in Section I, including legislation and rituals. To consider this in the context of race, what individuals can conceive of is affected by the prevailing ideology. It is difficult in a racist society not to use "racial categories.” But one can still believe that racial categories should be outlawed and that those who are disadvantaged by them would "choose" such a frame. The societal frame may change much more slowly. It may pay no attention, for instance, to the views of the "reds"- the relevant frames are dictated by laws and systems of information-gathering, and those may be controlled by the greens. Alternatively, the vast mass of individuals who neither benefit nor lose from racism may "switch" their beliefs in a process of contagion—when a racist marries a liberal, their children may become liberal. The überideology of equality may make racist categorizations unacceptable to these individuals. That could lead to a system in which there is a sudden 
tilting of the societal perception when, for instance, those who find a racist categorization unacceptable become a majority.

\section{Conclusion}

Ideologies (belief systems, including those that determine the admissible categories, the "lenses" through which the world is perceived) are constrained by "higher-order beliefs" that can be thought of as intrinsic values (or an überideology). Beliefs about the acceptability of slavery were affected by the überideology of equality. Notions of equality made it necessary to invent and institutionalize various racial categories to justify certain economic relations. But changed notions of equality eventually made the notion of race as a basis of slavery—and eventually as an admissible category for other purposesunacceptable.

We don’t explain changes in überideology, just as we don’t explain changes in technology. Changes arise partly from internal dynamics-a dialectic of ideasand partly from changes in economics and in the opportunities to influence belief systems. It is not just economics. "Motivated beliefs" may help explain change, but not in the standard way. The Protestant Reformation emphasized individuals' relationship with God, not mediated by authority; and the equality of men at least arguably evolved out of these religious conceptions. Ideas have their own dynamic. 
For economists to ignore the factors that affect how we process information as part of the interpretation of economic change would be as wrong as to ignore the evolution of technology itself.

We agree with the sociologists and anthropologists on the need to incorporate social constructs (belief systems) into our models of institutions and development. But these scholars have left out that social constructs need to be understood as an equilibrium. Ideology is a state variable in our theory of change and development (as also in that of Greif and Laitin 2004). The theory we have sketched helps explain societal rigidities. Beliefs shape not only behavior but perceptions. Beliefs typically do not change overnight. If there were a different set of beliefs that might be good for societal elites_or even for society as a wholeno one (including the government) could manage that change. Untouchability, for example, has persisted, at least in some parts of India, despite its abolition. At the same time, the approach of this paper provides elements of a theory of societal change. Technology, contacts with the outside world, endogenous changes in power and wealth, matter not just directly but because they can lead to changes in ideology. 


\section{References}

Bénabou, Roland. “Groupthink: Collective Delusions in Organizations and Markets.” Manuscript, Princeton University, 2008.

Bénabou, Roland and Tirole, Jean. "Belief in a Just World and Redistributive Politics.” Quarterly Journal of Economics, 2006, 121(2), pp. 699-746.

Bertrand, Marianne; Chugh, Dolly and Mullainathan, Sendhil. "Implicit discrimination.”American Economic Review, Papers and Proceedings, 2005, 95(2), pp. 94-98.

Chaplin, Joyce E. “Natural Philosophy and an Early Racial Idiom in North America: Compar-ing English and Indian Bodies.” William and Mary Quarterly, 1997, 44(1), pp. 229-252.

Compte, Oliver and Postlewaite, Andrew. “Confidence-Enhanced Performance.” American Economic Review, 2004, 94(5), pp. 1535-57.

Cowlishaw, Gillian. Rednecks, eggheads, and blackfellas: A study of racial power and intimacy in Australia. Ann Arbor, University of Michigan Press, 1999.

Davis, David Brion. The problem of slavery in the age of revolution 1770-1823. New York, Oxford University Press, 1975.

Dirks, Nicholas B. Castes of mind: Colonialism and the making of modern India. Princeton, Princeton University Press, 2001.

Dirks, Nicholas B. The scandal of empire: India and the creation of imperial Britain. Cambridge, Harvard University Press, 2006.

Douglas, Mary. How institutions think. Syracuse, Syracuse University Press, 1986.

Fields, Barbara J. “Ideology and Race in American History” in Region, race, and reconstruction, Ed. J. Morgan Kousser and James M. McPherson, New York, Oxford University Press. 1982, pp. 143-47. 
Greif, Avner and Laitin, David. “A theory of endogenous institutional change,” American Political Science Review, 2004, 98(4), pp. 633-52.

Hoff, Karla and Pandey, Priyanka. "Discrimination, Social Identity, and Durable Inequalities.” American Economic Review, Papers and Proceedings, 2006, 96(2), pp. 206-11.

Hollinger, David A. “Amalgmation and Hypodescent: The Question of Ethnoracial Mixture in the History of the United States.” American Historical Review, 2003, 108 (5), pp. 1363-1390.

Hughes, Robert. The fatal shore: The epic of Australia's founding. New York, Knopf, 1987.

Hume, David. An enquiry concerning the principles of morals. London, A. Millar, 1751.

Laurence, Stephen and Margolis, Eric. “Concepts and Cognitive Science.” In Concepts: Core reading, eds. Margolis and Laurence, Cambridge, MIT Press, 1999, ch. 1.

Loury, Glenn C. The anatomy of racial inequality. Cambridge, Harvard University Press, 2002.

McQueen, Humphrey. "Racism and Australian Literature.” In Racism: The Australian experience, ed. Frank S. Stevens, Vol 1: Prejudice and Xenophobia, New York, Taplinger Press, 1971, pp. 115-122.

Myrdal, Gunnar. Asian drama: An inquiry into the poverty of nations. New York, Pantheon, 1968.

North, Douglass C. Understanding the process of economic change. Princeton, Princeton University Press, 2005.

Rabin, Matthew; Schrag, Joel L. "First Impressions Matter: A Model of Confirmatory Bias.” Quarterly Journal of Economics, 1999, 114(1), pp. 3782. 
Ritterhouse, Jennifer. Growing up Jim Crow: How black and white Southern children learned race. Chapel Hill, University of North Carolina Press, 2006.

Smith, Pamela, Nils B. Jostmann, Adam D. Galinsky, and Wilco W. van Dijk. “Lacking Power Impairs Executive Functions.” Psychological Science, 2008, 19 (5), pp.441-47.

Tatz, Colin M. “Aborigines: Law and Political Development.” In Racism: The Australian Experience, ed. Frank S. Stevens, Vol 2: Black versus White, New York, Taplinger Press, 1972, ch. 8.

Thucydides, The Peloponnesian war. Trans. Richard Crawley. New York, Modern Library, 1951. 